\title{
Intersetorialidade em redes de políticas públicas para consolidar o Sistema de Garantia dos Direitos: 0 que aprendemos nesses 30 anos de Estatuto da Criança e do Adolescente? ${ }^{1}$
}

\author{
The intersectoriality in the public policies \\ networks to consolidate the rights guarantee \\ system: what do we learn in these 30 years of child \\ and adolescent Statute?
}

\author{
Zelimar Soares Bidarra* \\ Ana Lucia Dourado**
}

\begin{abstract}
Resumo: Esse artigo trata do processo de construção da intersetorialidade em redes de políticas públicas como uma condição para que o Sistema de Garantia dos Direitos (SGD) consiga alcançar sua finalidade de ofertar a proteção integral para as crianças e os adolescentes brasileiros. Parte-se de premissas estabelecidas no Estatuto da Criança e do Adolescentes para que o SGD seja o resultado de ação pactuada e em complementaridade entre as políticas públicas. No entanto, o resultado buscado está em contradição com a racionalidade instrumental que organiza a produção e reprodução social na ordem burguesa. Tendo esse pano de fundo, o texto que segue foi elaborado com base em resultados de pesquisas de campo com o objetivo de demonstrar como é possível desafiar a lógica fragmentária dessa racionalidade para construir experiências de implementação de políticas públicas que se pautem na lógica da articulação e da pactuação coletiva. Além de desenhar formatos institucionais de prestação de serviços que avancem na concretização da garantia dos direitos fundamentais. Para essa demonstração de viabilidade, recorreu-se à experiência de estruturação da Rede Intersetorial de Proteção Social (RIPS) de Toledo/PR.
\end{abstract}

Palavras-chave: Intersetorialidade, Redes, Políticas Públicas, ECA, SGD

\footnotetext{
* Doutora em Educação pela Unicamp. Professora do Bacharelado e do Mestrado em Serviço Social (PPGSS), Professora do Mestrado e do Doutorado em Desenvolvimento Regional e Agronegócio (PGDRA) na Universidade Estadual do Oeste do Paraná - Unioeste/Toledo. Professeure Associée de l'Université Laval (Québec/Canada). Líder do Grupo de Pesquisa e Defesa dos Direitos Humanos Fundamentais da Criança e do Adolescente (GPDDICA)/CNPq. E-mail: zelimar@yahoo.com.br.

*** Mestranda em Serviço Social (PPGSS)- Unioeste/Toledo e Bacharel em Serviço Social. Membro do Grupo de Pesquisa e Defesa dos Direitos Humanos Fundamentais da Criança e do Adolescente. E-mail: anadourado_95@hotmail.com.

${ }^{1}$ O presente artigo contém dados de projetos de pesquisas desenvolvidos pelas autoras e que foram devidamente autorizados por Comitê de Ética em Pesquisa (CEP)/Unioeste, por meio do Parecer n. 2.442.045/2017 e Parecer n. 2.676.711/2018.
} 


\begin{abstract}
This article addresses the issue of the intersectoriality building of process in public policies networks. These networks are a condition for the rights guarantee system (RGS) to offer a comprehensive protection for Brazilian child. It starts with premises established in the Statute of child and adolescent so that the RGS is the result of an agreed action and in complementary between public policies. However, this result sought is in contradiction with the instrumental rationality that organizes social production and reproduction in the bourgeois society. Against this background, the text follows was prepared based on results of field research and aims to demonstrate how it is possible to challenge the fragmentary logic of this rationality to build experiences of implementing public policies based on the logic of articulation and the collective agreement to design institutional formats for the provision of services that advance the realization of guarantee of fundamental rights. For this demonstration of viability the structuring experience of the Social Protection Intersectoral Network (RIPS) of Toledo - PR was used.
\end{abstract}

Keywords: Intersectoriality, Networks, Public Policies, Statute, RGS

Recebido em 06/07/2020. Aceito em 30/07/2020.

\title{
Introdução
}

É necessário discutir os desafios inerentes aos seus processos de construção para entender a importância do trabalho intersetorial, interinstitucional, interdisciplinar, e suas expressões sob os formatos das redes de proteção. Tratar da constituição do trabalho intersetorial no Brasil implica reportar-se à lógica de proteção social que está inscrita na Constituição Federal de 1988. No que diz respeito à área da infância, assumir as prerrogativas estabelecidas pelo Estatuto da Criança e do Adolescente - ECA, Lei n. 8.069/1990 (BRASIL, 1990 e atualizações).

A Constituição afirma princípios de respeito aos direitos humanos, de igualdade de todos perante a lei, de não discriminação e eliminação de todas as formas de preconceitos [...]. Estes princípios devem servir como fundamento de prestações positivas, ou seja, ações efetivas propostas e operacionalizadas pelo poder público para concretizar a democracia social, econômica e cultural [...] (BIDARRA; OLIVEIRA, 2013, p. 230).

Ainda, ressaltam-se a importância e a finalidade do trabalho intersetorial entre políticas públicas para o processo de construção de relações institucionais mais democráticas. Por isso a pertinência de buscar seu desvendamento e realizar a análise de sua processualidade.

No presente artigo, a discussão sobre os desafios do trabalho intersetorial foi feita mediante o desenvolvimento de pesquisas ${ }^{2}$ que se debruçaram a entender uma questão dotada de

\footnotetext{
${ }^{2}$ Títulos: a) Análise de fatores inibidores à implantação de protocolos intersetoriais de atendimento na Rede Intersetorial de Proteção Social de Toledo (RIPS)/PR (CAAE: 80419617.0.0000.0107/CEP-Unioeste, desenvolvida entre os anos de 2017 a 2019). Para o desenvolvimento dessa pesquisa, contou-se com o apoio do CNPq, mediante a concessão de bolsa de Produtividade
} 
grande complexidade, qual seja: especificação e implementação de protocolos intersetoriais em uma rede de proteção entre os serviços das diversas políticas públicas para os atendimentos às crianças e aos adolescentes vítimas de violações de direitos e de violências.

A estruturação da ação intersetorial e em redes no âmbito das políticas públicas está diretamente vinculada ao processo de reconhecimento dessas violações e violências como problema público, social, no contexto da comunidade internacional e brasileira. Com esse tipo de ação, pretende-se obter a atenção qualitativa e abrangente, para os problemas decorrentes das realidades das violações de direitos e das violências contra a infância. Desde o final dos anos 50 do século XX, inúmeros são os esforços para que sociedades e governos se comprometam a construir e aprimorar os ambientes normativos e organizacionais favoráveis ao desenvolvimento de práticas intersetoriais e de medidas para proteção jurídica e social dos direitos humanos de crianças e aos adolescentes (NETO, 2015).

No Brasil, os registros de tais esforços datam da segunda metade dos anos 80, no bojo da movimentação que culminou com a aprovação do Estatuto da Criança e do Adolescente (ECA). Sendo ele um marco histórico na enunciação da ideia de que tal proteção se efetiva mediante a existência de práticas que dialogam, se vinculam, se conectam e se articulam por saberes diferenciados que partilham objetivos comuns, sob o formato institucional de um sistema de garantia dos direitos (SGD) humanos fundamentais (NETO, 2007).

A premissa de que a proteção dos direitos se viabiliza mediante a pactuação de objetivos e a articulação de finalidades, pelos entes políticos de uma coletividade, denota o caráter inovador do Estatuto, principalmente no aspecto atinente às responsabilidades para que se efetive a garantia da proteção social. É sabido que essa Lei reconhece que a família, a sociedade e o Estado são entes solidários para a especificação e a implementação das medidas que tornam acessíveis o usufruto dos direitos, bem como para o combate às violações e às violências. Para a materialização dessa solidariedade, há de se considerar o caminho definido pelo Art. 86 do Estatuto que, em consonância com o espírito da Convenção dos Direitos de 1989, reconhece como sistêmico o movimento de compartilhamento e de complementariedade da atuação entre organizações governamentais e não governamentais (NETO, 2007). No cerne do Art. 86, há o reconhecimento da intersetorialidade e da interdisciplinaridade como premissas estruturantes para a construção de um SGD, o qual se tornou detalhadamente especificado com a Resolução n. 113/2006 do Conselho Nacional dos Direitos da Criança e do Adolescente (CONANDA), a qual consolida o entendimento de que:

Art. $1^{\circ}$ O Sistema de Garantia dos Direitos da Criança e do Adolescente constitui-se na articulação e integração das instâncias públicas governamentais e da sociedade civil, na aplicação de instrumentos normativos e no funcionamento dos mecanismos de promoção, defesa e controle para a efetivação dos direitos humanos da criança e do adolescente, nos níveis Federal, Estadual, Distrital e Municipal (CONANDA, 2006, s/p).

É inimaginável tratar da garantia e da efetivação dos direitos para a infância brasileira sem levar em conta o percurso prospectado pelo Estatuto, ainda que nessas três décadas de vigência

em Pesquisa; e da Fundação Araucária na concessão de bolsa de iniciação científica (PIBIC) para o projeto, intitulado: Catalogação de fatores inibidores à implantação de protocolos intersetoriais na Rede Intersetorial de Proteção Social de Toledo (RIPS); b) A construção de protocolos como uma expressão do trabalho intersetorial: uma experiência no município de Toledo-PR (CAAE: 89659118.1.0000.0107/CEP-Unioeste - desenvolvida no ano de 2018, com a colaboração de acadêmica e que possibilitou a geração de dados empíricos utilizados no desenvolvimento de um Trabalho de Conclusão de Curso/Curso de Serviço Social da Unioeste - Câmpus de Toledo. 
se experimentem as dificuldades/adversidades e os implementadores da Lei sejam desafiados a demonstrar sua maturidade institucional.

Com vistas a esse fim, desde o início da vigência do Estatuto, em 1990, porém com maior robustez, a partir dos anos 2000, diversas realidades municipais e estaduais encaram algumas dessas adversidades e experimentam os desafios para a criação (ou fazerem avançar) dos espaços de articulação e de ações coordenadas que englobem e favoreçam ao diálogo entre os entes políticos responsáveis pela proteção. A finalidade é a construção de ações pactuadas/negociadas entre os serviços e as práticas profissionais que integram as redes das políticas públicas setoriais para que se ordene e se dinamize o SGD.

A necessidade de se avançar na estruturação desse Sistema pode ser observada nas cifras relativas às realidades das violações de direitos e das violências contra crianças e aos adolescentes $^{3}$, as quais denunciam a incapacidade do Estado brasileiro em cumprir plenamente com a promessa da proteção integral inscrita no Estatuto. Mas, com vistas a produzir mudanças nessas realidades, o Estado tem adotado a estratégia de desmembrar os compromissos em documentos específicos que atribuem competência de intervenção para algumas áreas.

Em um breve panorama acerca da atuação governamental (nas esferas da união e de uma unidade da federação) sobre o problema público das violações de direitos e das violências perpetradas contra a infância brasileira, é possível observar a presença de marcos que desenharam esse compartilhamento de compromissos, sendo:

Em âmbito nacional

- $\quad 1^{\circ}$. Plano Nacional de Enfrentamento à Violência Infanto-Juvenil - PNEVSCA (2000) e 2․ Plano Nacional de Enfrentamento à Violência Infanto-Juvenil PNEVSCA (2013).

- Programa de Combate ao Abuso e à Exploração Sexual de Crianças e Adolescentes - Programa Sentinela (2001).

- Política Nacional de Redução da Morbimortalidade por Acidentes e Violências (2001).

- Programa de Ações Integradas e Referenciais de Enfrentamento à Violência Sexual Infanto-juvenil - PAIR (2002).

- Política Nacional de Assistência Social - PNAS (2004) e Sistema Único de Assistência Social - SUAS (2005).

- Política Nacional de Promoção da Saúde (2006).

- Plano Nacional de Educação em Direitos Humanos (2006).

- Programa Nacional de Direitos Humanos - PNDH 1 (1996), PNDH 2 (2002), PNDH 3 (2009, atualizações em 2010-2012).

Em unidade da federação: o estado do Paraná

- 1 Plano Estadual de Enfrentamento à Violência contra Crianças e Adolescentes (2005).

- 2 Plano Estadual de Enfrentamento à Violência contra Crianças e Adolescentes (2010).

\footnotetext{
${ }^{3}$ Para uma rápida alusão a essas cifras, vide dados dispostos no Sistema de Informação para Infância (SIPIA) e no SINANDatasus, os quais têm servido de referência para as estatísticas organizadas e divulgadas nos Mapas da Violência no Brasil (por Júlio Jacobo Waiselfisz) e Atlas e Anuários do Fórum Brasileiro de Segurança Pública (FBSP) e do Unicef/Brasil.
} 
- Plano Decenal dos Direitos da criança e do adolescente ${ }^{4}$ do estado do Paraná: 2014-2023.

Dentre os documentos acima listados, cabe reconhecer a diferencial importância do $1^{9}$. PNEVSCA, aprovado em 2000, construído no contexto das cobranças de profissionais e de atores sociais que militavam na área da defesa dos direitos da criança e do adolescente. Eles reivindicaram a instituição de programáticas de atendimentos e de enfrentamento para as circunstâncias das violações de direitos que culminavam nos mais diversos tipos de violência. A concretização das diretrizes, dos eixos estratégicos e dos objetivos com relação ao atendimento e ao enfrentamento às violações e às violências que foram estabelecidos no $1^{\circ}$. PNEVSCA (BRASIL, 2002) tornaram-se responsabilidades setoriais e foram alojadas nas intervenções profissionais no âmbito:

a) da área da saúde por meio: da Política Nacional de Saúde (PNS)/2001, da Política Nacional de Redução da Morbimortalidade por Acidentes e Violências/2001, da Política Nacional de Promoção da Saúde (PNPS)/2006.

b) da área da assistência social por meio: do Programa de Combate ao Abuso e à Exploração Sexual de Crianças e Adolescentes - Programa Sentinela (2001), dos Programas e Ações desenvolvidos em Centro de Referência (Especializado) de Assistência Social - CRAS/CREAS - (a partir de 2005).

c) da área da segurança pública e da justiça por meio: Programa de Ações Integradas e Referenciais de Enfrentamento à Violência Sexual Infanto-juvenil - PAIR (2002).

d) da área da educação: Escola que Protege (2004)

No âmbito das iniciativas proporcionadas por essas políticas e programas, fora em atendimentos particularizados ou em atividades educativas de mobilização comunitária, o enfoque e a abordagem permaneceram na setorialização, no atendimento isolado e fragmentado, focado exclusivamente na criança ou no adolescente vitimado.

Esse fato permite afirmar que os serviços e as intervenções profissionais correspondentes aos níveis e eixos das políticas públicas setoriais tenderam a elaborar propostas de atuação em formato intrasetorial, fragmentado e com fácil pulverização no cotidiano dos serviços. O mais complicado é que, na esfera dos atendimentos dessas políticas públicas, ainda hoje convivemos com a precariedade e até mesmo a ausência da padronização, da rotinização ou de protocolos intersetoriais e interdisciplinares. $O$ que se traduz na impossibilidade (ou compromete a qualidade) da avaliação da eficácia e da efetividade dos atendimentos prestados (BIDARRA; CESCONETO, 2020).

Isso nos revela a prevalência de um tipo de racionalidade (instrumental) que impõe como lógica de funcionamento a separação e a fragmentação das respostas formuladas pelo aparato estatal para as vivências das desigualdades e das contradições na sociedade burguesa.

o predomínio dessa racionalidade não favorece a construção de um ambiente social que busca a correspondência da atuação para com a lógica da interconexão e da complementaridade

\footnotetext{
${ }^{4}$ É importante ressaltar que a versão do Plano Decenal Nacional não foi finalizada até o momento em que se redigiu esse artigo (julho/2020). Também, para efeito de registro, damos a conhecer que não se encontra disponível em nenhum ambiente da rede web, seja sítios de órgãos governamentais ou não-governamentais, a versão preliminar de Plano Decenal, construída com base nas referências expressas pelas Resoluções 161/2013 e 171/2014 do CONANDA e que foi posta para Consulta Pública, mas que o resultado não é de conhecimento público. Todavia, há de se ressaltar que governos estaduais e municipais elaboraram suas versões de Plano Decenal, como foi o caso do estado do Paraná.
} 
que são inerentes às premissas e à concepção do SGD. Disto decorrem muitas das dificuldades para tornar o funcionamento desse Sistema viável, no curso desses 30 anos de vigência do ECA.

Em busca de respostas e soluções para os limites intrínsecos a essa realidade, nossas pesquisas investigaram e analisaram estruturas, funcionalidades e operacionalidade de políticas públicas setoriais que estão incumbidas de assegurar o enfrentamento e o atendimento às violações de direitos e às violências impingidas às crianças e aos adolescentes brasileiros. A dedicação ao tema se inspirou na referência de Iamamoto (1992, p. 124-125) acerca do

[...] que se exige do profissional que se propõe a ser crítico? ... [de um lado] a capacidade de articular o particular com o geral. De outro lado, a pesquisa criadora da realidade com a qual trabalhamos, a que nos possibilite ultrapassar o discurso da mera denúncia, para a elaboração de propostas competentes e eficazes para melhorar a qualidade dos serviços prestados [...].

Posto isso, o presente artigo apresenta alguns dos resultados e das reflexões decorrentes de pesquisas de campo que foram desenvolvidas com atores do SGD, em nível municipal, que têm protagonizado o desafio de buscar desconstruir e superar a lógica da setorização e da fragmentação (a racionalidade instrumental) que fragiliza a atuação da rede de proteção. Dentre as constatações, destaca-se o estrangulamento presente na política pública brasileira no que diz respeito aos processos de construção e de especificação de protocolos de atendimentos, bem como a fragilidade dos fluxos e mecanismos operativos que assegurem o compartilhamento das intervenções. 0 trabalho de reversão da lógica fragmentária (racionalidade instrumental burguesa) precisa investir na construção de respostas conectadas de modo intersetorial, interdisciplinar e interinstitucional para situações concretas de violações de direitos e de violências contra crianças e adolescentes. Acredita-se ser essa a via para uma atuação do SGD que possa cumprir com a promessa de proteção integral às crianças e aos adolescentes brasileiros.

\section{Intersetorialidade: para desafiar a racionalidade instrumental (burguesa)}

A perspectiva escolhida para tratar da intersetorialidade é a de considerar dois processos (profícuos para nossa reflexão e) que foram destacados em trabalhos recentes (MONNERAT; SOUZA, 2014; PEREIRA, 2014; TUMELERO, 2015), são eles: a partilha de poder e a ação concertada. Há uma disposição comum aos processos de partilha do poder (na perspectiva gramsciana da socialização da política) e de ação concertada (da capacidade de construção de consensos) que tratam da disponibilidade para renunciar ao personalismo e à centralização do comando com vistas a fortalecer iniciativas que representem uma construção coletiva. Tal disponibilidade não está posta de antemão ou mesmo corresponde ao processo de implementação de políticas públicas. Visto que a lógica da fragmentação e da pulverização da racionalidade instrumental reforça, inclusive, que a partilha de poder e a ação concertada, a negociação horizontalmente construída, são dimensões incompatíveis com as rotineiras intervenções dos quadros técnicos dos órgãos estatais responsáveis pela execução das políticas públicas (BIDARRA, 2009; CARNEIRO; COSTA, 2004; INOJOSA, 1998).

Assim, a construção do trabalho intersetorial tem dois obstáculos e/ou desafios imediatos a serem enfrentados, quais sejam: 1) a necessária partilha (distribuição) de poder entre os atores sociais/profissionais. Isso para que relações horizontais possam ser o canal para as decisões e para as escolhas políticas a serem tomadas com relação à direção de convergência a ser impressa na prestação de serviços e 2) a disponibilidade para ação concertada, isto é: pactuar uma sinergia 
convergente, no melhor sentido dos esforços simultâneos, com vistas a construir as condições para as mudanças na racionalidade (política e operativa) que decorrem da instituição do trabalho intersetorial. Para avançar em tal perspectiva é primordial romper com as rígidas cercas setoriais que são refratárias às trocas e mantêm intocadas rotinas estabelecidas que protegem as consolidadas estruturas de mando e comando setoriais. Ultrapassar as resistências conservacionistas significa avançar sobre barreiras que se erguem para dificultar o trabalho intersetorial que visa à nova racionalidade na organização e no funcionamento da prestação de serviços.

A nova racionalidade deve se contrapor à recorrente prática personalista que tem pouca serventia para a moderação ou resolução de problemas complexos. A expectativa é a de que a cultura organizacional e institucional assimile a racionalidade da articulação. E que ela esteja assentada em valores que prevejam na intersetorialidade a capacidade de contribuir com processos que tornem mais factíveis as distribuições e os acessos aos recursos. Para que eles representem patamares satisfatórios de bem-estar, de qualidade de vida e de proteção da dignidade humana - a base política para intersetorialidade.

As perspectivas da partilha de poder e da ação concertada (construção de sinergias, forças que convergem para consensos legitimamente construídos) não podem ser relegadas quando se trata da intersetorialidade, visto que tais perspectivas se relacionam com a decisão da alocação de recursos humanos e materiais. Talvez isso justifique porque ora tenhamos estímulos e ora entraves para a existência da intersetorialidade, isto é: para organizar um processo mais participativo e inclusivo na implementação de políticas públicas.

A intersetorialidade é uma expressão diferenciada sobre como se pode refundar o processo de implementação das políticas públicas em consonância com a noção republicana de espaço público (BIDARRA, 2006). Isso com vistas a atender às expectativas de que se trata efetivamente da viabilização do interesse e da coisa pública. Inclusive na perspectiva da efetivação de direitos de cidadania viabilizados pelos acessos aos bens e serviços transferidos pelas políticas públicas, dado tratar-se da partilha da riqueza social que está compreendida no fundo público (SALVADOR, 2010).

Apesar de ser um termo recorrentemente utilizado no campo das políticas públicas, a compreensão acerca daquilo que define e pode tornar mais precisa a intersetorialidade ainda não se constituiu em consenso substantivo nas práticas profissionais e nas reflexões intelectuais daqueles que cotidianamente interagem nesse campo. A certeza compartilhada é a de que se trata de um termo polissêmico, passível de significados antitéticos (PEREIRA, 2014).

Numa sucinta incursão na literatura, como demonstrado na sequência, estão localizados os primórdios das discussões sobre o tema nos anos 1980, quando a ideia da intersetorialidade chegou a ser tratada como sinônimo de cooperação interorganizacional ou multipartidária (GRAY, 1989). No contexto de avaliações de experiências apoiadas pelo USAID, o trabalho desenvolvido por KALENGAONKAR; BROWN, 2000, p. 2 - tradução nossa) capturou como prevalente o seguinte entendimento: "A cooperação intersetorial consiste na reunião de atores de setores do Estado, do mercado e da sociedade civil para obter um entendimento mútuo sobre um assunto e a partir disso negociar e implementar planos mutuamente aceitáveis para lidar com o problema que é identificado"s.

Nesse entendimento consta a ênfase em uma esperada relação de interação entre os entes políticos para que se possa produzir uma forma específica de implementação e de gestão de

\footnotetext{
${ }^{5}$ Redação original: "Intersectoral cooperation consists of bringing actors from the state, market and civil society sectors together to achieve mutual understanding on an issue and negotiate and implement mutually agreeable plans for tackling the issue once it is identified." (KALENGAONKAR; BROWN, 2000, p. 2).
} 
políticas públicas. Nele não há qualquer discordância entre as concepções sobre a intersetorialidade que estão expressas por referências intelectuais que se põem em campos distintos, são elas: as vertentes democrático-progressista e neoliberal. Os anos de 1980 e 1990 compõem uma conjuntura de acirrada defesa do projeto do neoliberalismo, cuja narrativa predominante era a da reforma (minimizadora) do Estado, isto é, de seu encolhimento do campo dos gastos sociais e dos direitos sociais. Dentro desse ambiente político-intelectual prevaleceu uma interpretação sobre a intersetorialidade que a vinculava às expectativas neoliberais. Passou-se a forjar um significado estrito e reducionista para a noção de intersetorialidade limitado à ideia de impedir a sobreposição da oferta de serviços. Como consequência, se ressaltou seu potencial gerencial e se empobreceu a capacidade política de produção dialogada e pactuada de entendimentos coletivos para um consistente acesso aos direitos de cidadania.

A partir da crítica a essa perspectiva reducionista se passou a pensar e a se focar na defesa da cooperação intersetorial como alternativa para a solução de problemas de grande complexidade que são objetos das intervenções de subáreas de uma mesma ou várias políticas públicas, tal como a questão da violência. Pode-se dizer que permanece atual essa forma de valorizar a intersetorialidade como uma mobilização de energias e de esforços coletivos pelos quadros técnicos das políticas públicas (KALENGAONKAR; BROWN, 2000). Mediante tal intersetorialidade, pretende-se elaborar respostas organicamente pensadas e estruturadas que representem a trama dos acordos entre aqueles que constroem as medidas de contraposição a uma racionalidade segmentadora e pulverizadora, que caracteriza a cultura institucional e a estrutura político-administrativa do Estado Moderno ${ }^{6}$. Reforça-se a convicção de que a intersetorialidade não decorre de rotinas instaladas, do que está "naturalmente posto". A atuação intersetorial precisa ser forjada pelos quadros técnicos implementadores de políticas públicas - aqueles que a literatura denomina como "burocratas do nível da rua" - street level (LIPSKY, 1969).

Para Mioto (2002), limitações e retardos com relação ao aprimoramento intelectual da atuação intersetorial ocorreram porque esses quadros técnicos adentraram no debate sobre a intersetorialidade e a organização do trabalho em redes de políticas públicas quando se vivia o início do processo de desmantelamento do financiamento das políticas públicas, no contexto das transformações societárias impostas pelo receituário neoliberal, que provocaram a reestruturação produtiva. Diante desse cenário, a elite dirigente apostou na emergência de um segmento intitulado por "terceiro setor". Ganharam espaço nesse debate as repercussões de experiências de intersetorialidade e de trabalho em rede que se ancoravam nas seguintes lógicas: a primeira refere-se à desresponsabilização do Estado e a segunda reafirma a responsabilidade do Estado para com a integralidade da atenção aos usuários das políticas públicas, para o quê precisa encontrar a melhor forma de articular os recursos disponíveis.

Em uma revisão da literatura sobre o tema da intersetorialidade, Akerman et al. (2014) reconhecem que tem prevalecido um processo de conhecimento que se faz pautado na descrição de experiências que buscam formular respostas para a qualificação do atendimento, dentro desse cenário de escassez dos investimentos nas políticas públicas. Não raro, ao tratar dessas experimentações, seus interlocutores associam as fragilidades à precarização ou inexistência dos recursos. Poucos se atêm a refletir sobre as dificuldades, os limites e as relações intrínsecas de disputas de poder e de fragilidades das pactuações, tanto das contrárias à racionalidade instrumental quanto daquelas que são constituintes de diversas experiências de implementação de políticas públicas. Invariavelmente, é possível observar o diálogo insuficiente entre as intercorrências que

${ }^{6}$ Para melhor detalhamento sobre o assunto vide a análise de TUMELERO (2015). 
saltam das experiências para com os apontamentos teóricos ressaltados na literatura. Em várias conclusões acerca dessas experiências, parece que o trabalho intersetorial e a formação de redes de políticas públicas estariam condenados ao fracasso em razão da não garantia dos recursos. 0 que impossibilitaria que as políticas públicas concretizassem formas de proteção social para o desenvolvimento da autonomia e da promoção humana.

Todavia, é preciso não perder de vista que a existência das políticas públicas na sociedade burguesa está diretamente relacionada a um tipo de racionalidade que não pretende assegurar a proteção integral, a autonomia e a promoção para todos os membros dessa sociedade. Por isso, segundo Bourguignon (2007), elas foram elaboradas para atuar de maneira desarticulada, fragmentada, setorizada, focalizada com vistas a reforçar uma modalidade de gestão hierárquica e centralizadora. $\mathrm{O}$ que representa uma atuação parcializada sob quaisquer que sejam seus objetos de intervenção. A compreensão desse nexo intrínseco é fundamental para a estruturação de um tipo de prática social que procure fazer seu enfrentamento, mediante o investimento em relações conectadas, horizontais e transversais para as trocas de saberes necessários entre os agentes encarregados de concretizar os fluxos entre serviços e benefícios transmitidos por essas políticas (BIDARRA, 2009).

Diante das dificuldades e dos desafios para tramar e conectar atuações, quando se consegue organizar o trabalho intersetorial e em redes, ele costuma se apresentar como uma inovação no modo de gestão pública, em razão da sua correspondência para com as necessidades de uma sociedade complexa. Esta articulação entre as políticas públicas, a partir dos agentes sociais que potencializam seu desempenho, possibilita uma intervenção cooperativa que contribui para uma atuação mais efetiva sobre a realidade e a construção de uma teia para a ação coletiva e interdisciplinar sobre os fenômenos sociais (GONÇALVES; GUARÁ, 2010).

A complexidade dos fenômenos de que se ocupam as políticas públicas, cada vez mais, torna evidente a necessária superação da racionalidade fragmentadora; além de exigir o engajamento interdisciplinar para lidar com as questões que devem ser objetos das tramas intersetorial e do trabalho em redes. Nesse sentido, diversas áreas de conhecimento têm se dedicado a refletir e a buscar caminhos, alternativas, formas, mecanismo e meios necessários para deflagrar e persistir com as tramas que oportunizam o cumprimento intersetorial da promessa de proteção social.

No que tange à política da área da infância, nesses 30 anos de vigência do ECA, o esforço tem sido o de forjar a convergência de objetivos para a concretização da intersetorialidade e da interdisciplinaridade. Nisso reside a riqueza do trabalho dos atores do SGD no processo de implementação das políticas públicas. Para que haja essa convergência, é necessário disputar o sentido da construção da ação política das práticas profissionais desses atores, de modo a desmobilizar os efeitos da racionalidade que incentiva a setorialização e a fragmentação, como mecanismos de disfarce do caráter residual e seletivo das políticas públicas na sociedade burguesa. Para essa disputa não se pode ignorar o campo das contradições, no qual estão imersas essas práticas, principalmente porque a concepção e o desenho desse Sistema, conforme Res. 113/2006 - Conanda (CONANDA, 2006), são contrários e incompatíveis com esse tipo de racionalidade fragmentadora e pulverizadora das atuações.

De acordo com as premissas dessa Resolução, o SGD deve atuar com base na articulação, na pactuação e na complementaridade para que as medidas para o combate e o enfrentamento das violações de direitos e das violências alcancem aos destinatários. Caso contrário, não se consegue reverter as situações cotidianas que comprometem a proteção integral e os direitos de cidadania para parcelas significativas de crianças e adolescentes brasileiros. Portanto, para atender às 
premissas estruturantes do SGD, é preciso lançar-se no desafio de se contrapor à racionalidade instrumental e buscar outro paradigma de embasamento para os processos da formulação e de implementação das políticas públicas. Tal desafio precisa ser experimentado em realidades concretas - em territórios onde as problemáticas e os quadros profissionais das políticas públicas setoriais têm encontros e embates cotidianos.

\section{Pontes e fluxos intersetoriais: a defesa da lógica de articulação para a concretização do SGD}

Compartilhamos com a assertiva de Baptista (2012, p. 189) de que a ideia de sistema presente que está inscrita na concepção do SGD tem correspondência com o estabelecimento de uma “[...] rede relacional intencionalmente articulada [...]" que depende de decisão política dos atores para começar e consolidar as tramas de interação interdisciplinar, intersetorial, interinstitucional que materializam a transversalidade da Política de Atendimento com vistas à garantia dos direitos de crianças e adolescentes. Uma vez que: "Projetar uma intervenção sobre determinados aspectos da realidade social a partir da ideia de redes implica considerar a existência de pontos de contato e de conexões [...]" (BIDARRA, 2009, p. 492).

Em busca de aprofundar os conhecimentos sobre um processo fomentador de contatos e de conexões, a discussão que segue tem como base os "achados" e as reflexões proporcionadas pelas pesquisas (nas modalidades exploratória e pesquisa-ação) desenvolvidas entre os anos de 2017 a 2019; no ambiente de construção de uma experiência de atuação em rede intersetorial no município de Toledo, localizado na região Oeste do estado do Paraná. Toledo é categorizado como município de grande porte, mais de 100 mil hab. (BRASIL, 2009) e conta com as estruturas de serviços compatíveis com porte para atenção à saúde, à educação, à assistência social e ao sistema de justiça e de direitos humanos.

De acordo com Bidarra e Cesconeto (2018), com a finalidade de construir medidas pactuadas e articuladas, sob o formato de protocolos, executáveis em fluxo operacional, para a concretização da proteção social, em 2015, alguns profissionais ("street level") com atuação circunscrita ao âmbito das políticas públicas setoriais decidiram investir na criação de uma prática intitulada: Rede Intersetorial de Proteção Social de Toledo/PR (RIPS). Essa experiência tornou-se conhecida por pensar estratégias, articular diálogos e acordos/pactuações sobre temáticas/problemas/ demandas postas às estruturas executoras de políticas públicas setoriais (das esferas municipal e estadual). Muitos são os resultados advindos desse processo, mas, como produto, tem-se a construção de protocolos intersetoriais de atendimentos para as pessoas em situações de violações de direitos e de violências.

A Rede Intersetorial de Proteção Social (RIPS) do município de Toledo é recente e está formada por serviços e por profissionais cujas atuações estão comprometidas em fazer avançar a garantia de direitos dos usuários. Nesses anos de existência da RIPS, há o envolvimento de atores do SGD, que oscila e abrange, desde profissionais das políticas públicas municipais e de órgãos do governo estadual até docentes e acadêmicos através de projetos de extensão universitária do Curso de Serviço Social da Universidade Estadual do Oeste do Paraná/Unioeste, câmpus Toledo. Essa Rede compreende um universo de práticas profissionais de caráter interdisciplinar, cuja organização conta com um trabalho sistemático de um grupo de profissionais que se intitula Equipe de Mobilização para a Intersetorialidade (EM-RIPS). 
Para favorecer aos momentos de estudos, de reflexão, de debates, de negociação de alternativas e de aprimoramento das práticas, a EM-RIPS auxilia na elaboração e na sistematização das propostas, discutidas com os profissionais da Rede. A finalidade é a da transformação das pactuações sob o formato de protocolos. Eles passam a orientar as práticas profissionais envolvidas com as temáticas/problemáticas tratadas no âmbito da RIPS. Reforça-se a importância de essa atuação estar referenciada em uma fundamentação teórica que oriente o sentido da intersetorialidade para uma forma de gestão participativa na implementação das políticas públicas, a qual respalde tanto a atuação destes profissionais, quanto a natureza e o conteúdo dos protocolos e dos fluxos estabelecidos. Dado que a intersetorialidade e a estruturação do trabalho em rede tratam de um contínuo exercício da relação teórico-prática.

No âmbito da RIPS é necessário estar atento ao fato de que não se pode prescindir de participar do debate das lógicas, lembradas por Mioto (2002), sobre o trabalho em rede (intersetorial). Haja vista uma delas defender a desresponsabilização do Estado e pressupor que a finalidade da intersetorialidade seja "resolver" a redução de investimentos na oferta de serviços, diante de uma propalada escassez de recursos. Segundo Bidarra (2009), esse tem sido um dos argumentos muito utilizado por estruturas do poder político ${ }^{7}$ para justificar a necessidade de uma intersetorialidade que se coloca como remendo para as falhas e buracos no sistema de proteção. A outra lógica, a que reafirma a responsabilidade do Estado para com a integralidade da atenção aos usuários das políticas públicas setoriais, vê na rede intersetorial a melhor forma de articular horizontalmente a atuação dos atores e o uso dos recursos. Isso com vistas à construção de pontes de interligação (protocolos e fluxos) para proporcionar uma cobertura mais abrangente e qualitativa das necessidades manifestas, dada a complexidade dos fenômenos de que se ocupam as políticas públicas.

A atuação de uma rede de proteção deve perseguir a efetivação da garantia dos direitos de forma mais universalizada e em consonância com os princípios da Constituição Federal e do Estatuto da Criança e do Adolescente. Impulsionados por esta perspectiva, tem-se trabalhado para consolidar o processo de institucionalidade da ação concertada que tem sido construída no espaço da RIPS-Toledo. Pela via da concertação, investe-se em condições para transcender um trabalho verticalizado, setorial e fragmentado. O objetivo perseguido é o de uma atuação horizontalizada entre profissionais das políticas públicas, a qual traduza a organicidade na prestação de serviços que configura a abrangência do SGD.

Para melhor conhecer e analisar essa experiência de construção da intersetorialidade pela via do exercício da partilha de poder e da ação concertada, pesquisas foram desenvolvidas para ouvir protagonistas ${ }^{8}$ da RIPS-Toledo. $O$ universo da pesquisa compreendeu profissionais das políticas públicas setoriais que integram a RIPS e cujas áreas/problemáticas de intervenção estão sendo objeto das pactuações/negociações para o estabelecimento de protocolos e fluxos de atendimentos. $O$ universo das pesquisas foi integrado por aproximadamente trinta profissionais que formavam equipes técnicas dos serviços das políticas setoriais. Os dados foram coletados junto a uma amostra de doze profissionais, os quais foram selecionados pelos seguintes critérios: ser integrante da Equipe de Mobilização da RIPS entre os anos de 2015-2019 e sua área de intervenção

\footnotetext{
${ }^{7}$ Para TEIXEIRA (2001, p. 26), o poder político “...não se confunde com autoridade ou Estado, mas supõe uma relação em que atores, com os recursos disponíveis nos espaços públicos, fazem valer seus interesses, aspirações e valores, construindo suas identidades, afirmando-se como sujeitos de direitos e obrigações."

${ }^{8}$ As manifestações desses protagonistas (aqui dispostas sob a classificação de E1, E2 sucessivamente) foram obtidas por entrevistas realizadas entre os anos 2018 e 2019, como estratégias de investigação de campo, estabelecidas nos projetos de pesquisa aprovados pelo CEP/Unioeste, conforme Pareceres descritos na nota n. 2.
} 
ter sido objeto das modificações empreendidas pelos primeiros protocolos estabelecidos pela RIPS. Com base nesses critérios, identificou-se a composição da amostra e se endereçou o convite para a participação nas pesquisas, e todos os contatados aceitaram.

As investigações de campo se pautaram na abordagem qualitativa e foram desenvolvidas com o uso da técnica da entrevista semiestruturada ${ }^{9}$, pela qual foram coletadas narrativas de profissionais da Rede. As entrevistas foram previamente agendadas e, em geral, aconteceram nos espaços sócio-ocupacionais dos entrevistados, por preferência e comodidade. Com base nas entrevistas, objetivou-se conhecer como eles compreendiam e avaliavam o significado desse trabalho intersetorial para o processo de efetivação da proteção social.

Com relação à historicidade e à importância da existência da RIPS-Toledo, os entrevistados destacaram o papel da pactuação ${ }^{10}$ e de seu processo que estar aportado na ideia da expansão da participação. "O principal desse processo foi conseguir envolver todos os sujeitos nas pactuações. Porque quando você constrói uma pactuação, ou chega a um consenso de algo que você ajudou a construiré muito diferente [...]" (E10, grifo nosso). A sustentação do trabalho nessa Rede se pauta na convicção de que todos os profissionais devem participar das proposições de alternativas e das buscas por enfeixá-las em decisões substantivas que representam avanços nas rotinas e na melhor qualificação da prestação de serviços aos usuários. "Então, o motivo que levou mesmo à participação foi o fato de nós não termos fluxos estabelecidos de atendimento em rede, claros e específicos para cada demanda [...]" (E8, grifo nosso).

A partir dos conteúdos expressos nas entrevistas, foi possível perceber semelhanças quanto às modificações efetuadas nas atuações dos profissionais que integram a RIPS. De acordo com os entrevistados, a partir das discussões e das reflexões sobre as formas de constituir o percurso intersetorial, houve a reconstrução de algumas práticas tidas como corriqueiras, por eles nominadas como tradicionais.

[...] então, foi feito o acordo que essas crianças [ficariam] o tempo mínimo possível para o atendimento [...]. Nesse sentido, o Protocolo [...] teve essa influência direta no nosso trabalho (E1, grifo nosso).

Foi o meu entendimento da necessidade de articular as ações do Estado para garantir o atendimento às necessidades das pessoas. Acho que sem essa articulação entre os diferentes setores fica difícil atender o ser humano na sua integralidade, eu tinha essa compreensão, tenho. Por isso, achei por bem interessante entrar na equipe (E12, grifos nosso).

Os momentos de reflexão sobre a ação profissional possibilitaram novos entendimentos sobre a temática posta para a pactuação. Desta maneira, pode-se destacar que "[...] a gente começou a rever algumas coisas do dia a dia do atendimento dessas crianças. Então assim, foi tudo muito passo a passo, então se elaborava a primeira etapa do primeiro protocolo se sentava, se discutia entre todas as políticas envolvidas nesse atendimento" (E1, grifos nosso). Foi mencionado o crescimento do respeito entre os diferentes profissionais, cujo avanço mais concreto ocorreu a partir dos momentos das pactuações.

\footnotetext{
${ }^{9}$ As falas dos entrevistados, quando inseridas no corpo do texto, estão diferenciadas pelo estilo em itálico. Outras em caixa de citação (com recuo de $4 \mathrm{~cm}$ ) com a finalidade de dar destaque aos relatos.

${ }^{10}$ Vale ressaltar que as pactuações não são realizadas exclusivamente pelos membros da Equipe de Mobilização, mas pelo conjunto dos profissionais diretamente envolvidos com as temáticas que são objetos das padronizações - protocolos e fluxos.
} 
Com isso, houve mais segurança para a redefinição de rotinas e de procedimentos entre os participantes da implementação, seja dentro de uma mesma política setorial e desta para com as outras. "As pactuações têm um processo; é um processo longo até elas ocorrerem, porque são vários encontros, vários diálogos e uma disposição de considerar o ponto de vista do outro setor, as potencialidades e limitações" (E7). Avançou-se na especificação de uma rotina de atendimento mais sistematizada.

Profissionais de diferentes segmentos que participaram dos momentos das discussões e das pactuações disseram se sentir vistos e ouvidos, enquanto política pública. Pois, até então, nem sempre se sentiam participando significativamente nas decisões.

Essa pactuação foi de extrema relevância para a política [...], porque foi a primeira vez que [...] passou a ter voz na temática [... e] no trabalho em rede. Até então havia uma escuta, mas uma escuta de casos específicos, não de como é o acolhimento para a rede [...], então inclusive já na primeira capacitação, houve o que chamou bastante atenção o envolvimento da profissional [...], as angústias [sobre como certos procedimentos aconteciam] (E5, grifos nosso).

A continuidade dos trabalhos da RIPS alimenta e reforça a necessidade de se avançar e consolidar a intersetorialidade entre os órgãos e as políticas públicas setoriais. Aqui se germina a convicção de que somente a lógica da articulação permite superar muitos dos entraves na execução dos serviços que decorrem da racionalidade da fragmentação. Para elucidar a força do processo local, destacam-se os fragmentos de relatos que recuperaram o caminho perseguido para forjar a articulação entre os diferentes saberes.

[...] nós percebemos que era comum o sentimento de necessidade de maior interlocução entre as políticas públicas, de formalização de algumas formas de atuação para dar mais fluidez a prática. Então, nesse processo, foram várias situações concomitantes, o desejo da chefia de estar aproximando as políticas públicas, uma necessidade que eu também vinha identificando e uma iniciativa que foi tomada por parte de uma política pública [...] de estar discutindo fluxos internos. (E3 - grifo nosso).

Então a gente contribuiu nesse processo buscando até conversar com os profissionais [...] como estava se dando esse processo até então, como era feito esse acompanhamento, quais eram os problemas (E2).

O compromisso com o fato de que a intersetorialidade respeite a interdisciplinaridade entre os saberes é uma orientação constantemente vigiada na e pela EM-RIPS, desde o seu primórdio. Porém, isso não significa que não se experimente uma série de embates e conflitos inerentes aos processos de disputa de poder e de saber. Mas, admitir a mudança significa ampliar a participação de modo que todos os membros da Rede são convidados a se engajarem e contribuírem com a diversidade dos saberes para a construção dos protocolos e dos fluxos.

Foi o meu entendimento da necessidade de articular as ações do Estado para garantir o atendimento as necessidades das pessoas. Acho que sem essa articulação entre os diferentes setores fica difícil atender o ser humano na sua integralidade eu tinha essa compreensão, tenho [...]. (E7, grifo nosso).

Os membros da Rede se sentem motivados e engajados no processo de busca pelo aprimoramento das formas de proteção dos sujeitos envolvidos na temática da violação de direitos e das violências, neste caso: as crianças e os adolescentes. Neste contexto, o resultado da RIPS é 
um "trabalho de várias mãos" 11 que busca desconstruir a lógica verticalizada de decisões e isso acontece "[...] porque quando não havia um comum acordo entre os integrantes, a gente preferia não levar isso adiante porque a ideia sempre foi muito de horizontalidade, de respeito às atribuições profissionais" (E3, grifo nosso).

Os esforços envidados para a construção de uma atuação horizontalizada que expresse o respeito aos limites, as atribuições dos demais profissionais e as competências das políticas públicas foram bastante destacados pelos entrevistados.

[...] eu lembro, por exemplo, da definição do papel daqui de cada equipe técnica. Ficou bem especificado qual era o papel da equipe [...], que é a perícia e qual é o papel das equipes que atuam no SUAS. Acho que isso foi importante para os operadores de direito entenderem a especificidade de cada atuação (E7 - grifo nosso).

[...] foi pactuado dentro das equipes de se ter uma priorização e se respeitar a individualidade dessas pessoas no momento do atendimento; para que não ocorressem essas situações de colocar no atendimento seus preconceitos e juízos de valores. Nesse sentindo, se respeitar enquanto indivíduo, enquanto uma pessoa que está ali naquele equipamento para seu atendimento relacionado à sua questão [...] e não os julgamentos outros que não dizem respeito à questão [...] em si (E2, grifos nosso).

Os percursos sobre como foram estabelecidas as pactuações estão diretamente vinculados ao processo de organização da RIPS. Pôde-se refazer um pouco do caminho trilhado a partir das narrativas, sob a perspectiva da experiência de cada profissional. Além de como tudo isso integra a história e a atuação na RIPS. Alguns aspectos deste movimento podem estar registrados nas "Memórias" (documentos utilizados para o registro das reuniões da Rede), porém não de forma particularizada e única como evidenciadas nos momentos das entrevistas.

A proporção em que a RIPS foi se consolidando e os profissionais amadurecendo o trabalho, com ações voltadas para uma articulação em rede, os resultados tomaram o formato efetivo de protocolos e de fluxos de atendimentos. Os protocolos e fluxos significam as pontes para a materialização da ação articulada em redes das políticas públicas e contribuem para efetivação dos direitos desses usuários.

[...] a elaboração de protocolos e fluxos significa 'construir pontos de contatos e conexões, ou seja, troca de saberes e intervenções profissionais que direcionam o movimento de atendimento para a satisfação e resolutividade do que foi demandado', sempre tendo em vista aprimorar e melhorar o atendimento ao usuário (E10).

Diante dessa construção coletiva, os sujeitos profissionais se sentem cada vez mais pertencentes ao processo, pois contribuem para que haja uma prática em consonância com a perspectiva da garantia dos direitos dos cidadãos.

[...] eu considero que todas as pactuações, [...] a gente percebe que há um processo assim: primeiro um fluxo bem definido; outro aspecto importante é que $o$ fato de todas as equipes terem conhecimento sobre esse processo, por-

\footnotetext{
${ }^{11}$ Essa expressão utilizada por uma das integrantes da EM-RIPS (Profa. Zelimar) no dia 19/10/2017 quando da Solenidade de entrega/publicização do terceiro Protocolo construído por essa modalidade de trabalho coletivo. Inclusive, a logomarca da RIPS é a síntese dessas "várias mãos” que articulam a convergência de ideias e de interesses (DOURADO, 2018).
} 
que nós temos na política [...] uma mudança constante de equipes, nas outras políticas também né [...]. E esse movimento fica muito claro, o profissional que hoje chega, ele faz os estudos desses Protocolos e ele consegue atuar tranquilamente. Então assim, considero que todas elas foram sadias ao passo que foram construídas pelos profissionais e os aspectos importantes seriam esses mesmos. $O$ fato de vocês terem algo fixo, algo que independentemente da mudança de governo né, isso tem permanência e que os profissionais se sintam mais seguros em algo que já está estabelecido e construído por eles (E6, grifos nosso)

Os relatos dos entrevistados ressaltam sobre o quanto a intersetorialidade é uma ponte para relações mais horizontais, mediante as quais se pode exercitar a partilha de poder, a ação concertada e a co-responsabilização, as quais concretizam a articulação em rede como um trabalho de "várias mãos".

A horizontalidade vivenciada na experiência da RIPS não é tarefa simples e nem ausente de conflitos e de contradições. No cotidiano, algumas atuações teimam em repor a lógica da fragmentação, da preservação da verticalidade das decisões e da atuação setorizada das políticas públicas. Pois, com a conservação dessa lógica, não se interfere e nem se provocam mudanças nas práticas acomodadas.

Então, eles estão sendo utilizados. 0 que a gente percebe é que a dificuldade em colocá-los em prática é realmente nos momentos daquilo que já foi pactuado, porque as equipes que chegam têm o conhecimento. Como eu falei, é um ponto positivo [o fato de] ela já ter um fluxo a seguir, mas sempre que há uma relação com outra política, nós temos uma dificuldade para executar [...]. A gente sente essa dificuldade e, também, em alguns momentos, como nós estamos vivenciando [...] quando há posicionamentos diferenciados [...]. Mas eles estão sendo colocados em prática, foram construídos, eles estão, sim, garantindo a execução específica [...] que é a avaliação que a gente está fazendo (E6, grifos nosso).

As dificuldades, para se colocar em prática as formas conectadas e complementares de atuação, estabelecidas pelos Protocolos foram ressaltadas por alguns dos entrevistados. Isso porque, na maioria das vezes, essas novas formas se contrapõem às rotinas daqueles que possuem uma prática solidificada, acomodada, sob a qual se acostumou a ter pleno domínio.

É difícil assim, na medida em que a gente parar pra pensar se o que a gente está fazendo está correto, então é difícil, mas por outro lado é produtivo, e faz a gente repensar o dia a dia da gente sabe! Porque à medida que você discute isso, você mexe com pessoas, você lida com outros colegas profissionais, [...]. Isso faz com que todo mundo reveja seu atendimento e nós temos que ter uma única linguagem. Então a gente pensa que, como construção final desse fluxo da RIPS [...], a gente vai conseguir construir o protocolo de forma que se não estivermos mais aqui, a gente muda, a gente sai, quem vier entenda que esse fluxo acontece. Eu mesma participei dessas discussões ao longo de muitos anos. Houve várias tentativas de construção desses fluxos, que por um motivo ou por outro, chegavam em um ponto e paravam por ali. Todo mundo ia trabalhar, porque as demandas dos serviços são muitas e como eram profissionais envolvidos de vários setores, acabou que terminava em determinado momento e não se voltava. Não tinha esse trabalho político e contínuo, 
como a RIPS está tendo agora. E isso eu acho fantástico para o nosso dia a dia, você ter uma base para você se pautar para poder fazer o trabalho. (E1 - grifos nosso).

Mas, rever o instituído é um desafio aceito pela RIPS. Há registros sobre o quanto os membros da RIPS valorizam esses passos e conquistas das novas formas de interação: "a alegria de ver tornar-se real o que antes era tema de discussões e estudos. E ainda, expôs a inovação da Rede que até então desconhece registro de algum outro grupo no Brasil que desenvolva tal ação" (RIPS-Memórias, 2016d, p.01, grifo nosso). A apropriação das novas rotinas intersetoriais pelos trabalhadores dos serviços das diferentes políticas públicas é um enorme desafio, o qual requer um esforço permanente de socialização de conhecimentos e de oferta de capacitações empreendidas pelos membros da EM-RIPS. Pois, nenhuma mudança de lógica quanto à forma de realização do trabalho, feita pela valorização de um saber coletivo e não personalista, é assimilada de imediato, aprioristicamente.

Eu diria que eles estão parcialmente aplicados na realidade hoje que esse movimento é muito dinâmico, não é algo que fica pronto que fica estabelecido porque o tempo passa $[\mathrm{e}]$ os profissionais às vezes perdem a importância disso, mudam-se os profissionais. Então é um cuidado, uma dificuldade, um desafio que a equipe tem que ter. A importância também desse elemento Equipe de Mobilização para estar se atentando a isso, estar resgatando isso, porque a intersetorialidade nunca vai estar pronta e posta porque ela é um movimento constante, um movimento político de afirmação daquilo que é horizontal contra uma estrutura que foi historicamente construída de forma verticalizada. Então é um constante rompimento porque isso é o que está posto; é uma expressão da nossa escolha de sociedade, [do] nosso modo de produção. Então, sempre vai ter essa estrutura muito marcada. (E3, grifos nosso).

[...] nós temos que avançar no sentido realmente de fazer com que ele seja da forma que ele está lá. [...] Nós temos experiência [...] que não estão sendo passados pelos Protocolos. Então têm algumas coisas que têm ainda que ajustar, mas assim, realmente é um avanço sem dúvida nenhuma e eu acho que só tem a melhorar, só tem que ajustar mais essas questões menores. (E4, grifos nosso).

Eles estão sendo aplicados, mas ainda não estão sendo cumpridos na sua totalidade [...]. Mas eu acho que na totalidade de todos os processos sim, eles são aplicados de alguma forma, mas em algum momento um ou outro profissional esquece de alguma questão ali. Mas o Protocolo não é difícil de pôr em prática, mas eu ainda considero que está em fase de apropriação do Protocolo. (E7, grifos nosso).

Os aspectos manifestos pelos entrevistados com relação à pertinência do trabalho desenvolvido no âmbito da RIPS condizem com os argumentos teóricos de que a construção da trama que viabiliza uma rede intersetorial não é algo pronto e nem fácil de ser colocado em prática. Uma vez que se contrapõem às práticas enraizadas de verticalidade de comando.

[...] uma coisa muito difícil que eu considero é a resistência das equipes na mudança. Não é nem se essa mudança vai ser positiva ou negativa, que isso a gente só vai conseguir analisar no futuro, mas a resistência de alguns profissionais; e eu estou falando isso analisando a política de assistência (...). 
Criar uma proposta intersetorial significa sair da sua comodidade, do seu fazer, ter que repensar isso, eu acho que essa é uma das dificuldades. (E12).

A despeito das dificuldades experimentadas, os entrevistados têm uma avaliação positiva sobre os resultados obtidos com a operacionalização dos Protocolos e dos Fluxos. Principalmente no que diz respeito ao repensar as práticas profissionais, além de melhoras na interlocução e na efetivação da co-responsabilidade entre políticas públicas setoriais, tais como: “Então o resultado é basicamente a reflexão visando à mudança necessária, à ação que precisa para que a gente fale uma única linguagem (E1, grifo nosso).

A unificação da linguagem para assegurar a consistência do serviço prestado, com vistas a concretizar as medidas de proteção social, apareceu nas entrevistas como um equivalente da noção de "padronização".

[...] eu acho que isso é um resultado positivo, porque quando há o diálogo entre as equipes, a gente visualiza responsabilização por aquilo que está se fazendo, o interesse e, também, o aperfeiçoamento dessas equipes, algo que antes a gente não parava para pensar. (E2, grifos nosso).

É, eu acho que na verdade organizou o procedimento, então o modo como se dá todo o processo [...] já está um fluxo claro de como acontece, como deve ser feito, quais serviços são acionados, qual a atuação de cada setor. Então sim, ele dá resultados e os resultados são esses: é uma organização do fluxo, articular os diferentes setores em prol da garantia dos direitos da criança e do adolescente [....] (E7, grifos nosso).

Porque olhando para outras realidades, [...] não existem padronizações, não existe esse esforço das pactuações porque é algo realmente difícil de ser feito, exige tempo, exige compromisso, exige humildade. Então, e assim, as situações [...] elas ficam à mercê da compreensão profissional daquele momento do profissional que está. Às vezes é mais comprometido ou menos, tem visões diferentes sobre a temática. Então, acho que isso contribuiu demais só que é isso a luta pela aplicação disso porque se a gente não conseguir aplicar infelizmente todo esse esforço ele fica sem valor. (E3, grifos nosso).

As posições acima explicitadas nos fazem acreditar que a construção e a aceitação de uma padronização coletivamente estabelecida decorrem do engajamento e do compromisso assumidos pelos atores da Rede. Eles veem mais sentido nesse caminho do que busca para implementar as políticas públicas em consonância com o acúmulo de saberes e de normatizações para a política da área da infância.

Os avanços assim, principalmente na qualidade e na perspectiva do atendimento; hoje você tem um direcionamento, desde o início até o desligamento. Nós temos a qualificação desse processo, então não é algo que depende de cada profissional ou não, nós tivemos muitos avanços relacionados à intervenção das equipes técnicas, mas também da rede de proteção (E6, grifos nosso).

A realização das pesquisas possibilitou que as pesquisadoras investigassem minuciosamente e refletissem sobre a prática intitulada RIPS-Toledo; a fim de se obter uma avaliação (preliminar) de seus atores sobre os resultados, até então, alçados com os esforços para reconstruírem seus cotidianos. Dentre as dificuldades apontadas sobressaiu aquela que se reporta às 
disputas de poder de comando para a conservação das atitudes hierarquicamente verticalizadas. Sposati (2006, p. 137) produziu um relato sobre sua experiência com a intersetorialidade quando esteve na condição de Secretária de Assistência Social do município de São Paulo. De tudo que foi experimentado, ela afirmou que: “[...] me mostraram que a aplicação de intersetorialidade não permite ter um padrão ou uma referência absoluta ou homogênea. Não pode haver nada absoluto, principalmente no Brasil, onde ainda ensaiamos políticas públicas democráticas e participativas". Esta argumentação nos ajuda a entender o caso analisado por nossas pesquisas, em que não se partiu de um modelo pronto para colocá-lo em prática. Mas, sim, da busca de um envolvimento e de um comprometimento daqueles que aceitaram o desafio de iniciar esta rede intersetorial. Em sendo assim, outros municípios não conseguirão colocar em prática o modelo da RIPS-Toledo, mas tê-lo como uma inspiração que necessita da adaptação para cada realidade concreta. Uma vez que

a intersetorialidade desenvolve um saber resultante da integração ou das áreas de contato. O que a move, sob o princípio da convergência, é o pacto de uma ação coletiva, integrada para um objetivo. Ela causa mudanças na cultura da gestão e na cultura dos agentes institucionais. A ideia de pacto de gestão vai além da solução de problemas ou do aumento da capacidade de resolução. Produz uma nova inteligência institucional, um novo domínio da realidade e traz o debate da inovação, superando o modelo da resposta pronta e única. Com isto, permite a porosidade democrática no modelo de gestão que possibilita enfrentar novos problemas, criar nova linguagem e novas respostas (SPOSATI, 2006, p. 140).

Assim, pode-se dizer que, com a RIPS, investe-se no caminho das pactuações para construir a intersetorialidade, pois mais do que um novo modelo de gestão, as decisões devem ser pautadas no respeito, na horizontalidade das relações e das trocas de saberes. "[...] é necessário que tenha fluência uma vez que a falta de conhecimento ou compreensão da prática pode dificultar os necessários momentos de consenso e até a mudança de postura" (E11). Os entrevistados valorizaram as pactuações como eixo central para a construção dos protocolos e dos fluxos. Estas tentativas para a construção do trabalho intersetorial e em rede não foram e não estão sendo fáceis. Porém, a cada dia tornam-se mais necessárias, considerando a realidade em que estamos inseridos.

\section{Considerações Finais}

Nesse momento em que celebramos os trinta anos de vigência do Estatuto da Criança e do Adolescente (ECA), vale reiterar a importância e a valorização de processos participativos para a construção da intersetorialidade nas redes de proteção social. Esses processos são pertinentes porque potencializam uma atuação mais abrangente e interdisciplinar entre os atores do Sistema de Garantia dos Direitos (SGD) na área da infância. Além de vincular instituições que têm o mesmo foco temático para a melhor consecução de objetivos da Política de Atendimento aos direitos da criança e do adolescente.

A integralidade deve ser a expressão das capacidades combinadas do Sistema de Garantia dos Direitos (SGD), efetivadas através do conjunto dos serviços desenvolvidos pelas políticas básicas e especiais. Isso demanda a construção de diálogos e pactuações entre aqueles que estão encarregados de operacionalizar as políticas de saúde, educação, assistência, cultura, segurança 
pública e de justiça, as quais isoladas ou justapostas não alcançam a cobertura e a resolutividade necessárias, nem mesmo no interior de seus próprios campos de atuação (BIDARRA, 2009, p. 495).

Todavia, para que uma rede intersetorial tenha condições de efetivar a proteção dos direitos, é essencial que aconteçam a articulação e a integração das ações entre as instâncias do poder público e das organizações da sociedade civil. Somente por esse caminho é possível alterar a percepção predominante das instituições como sendo, exclusivamente, órgãos centrais e hierárquicos. Necessita-se de um tipo de mudança que permita materializar, em nível local, o compartilhamento das responsabilidades, dos objetivos e dos compromissos em prol do bem-estar da criança e do adolescente brasileiros.

A despeito de fatores atinentes ao tipo de racionalidade dominante na sociedade burguesa, a qual organiza uma prestação de serviços governamental e não-governamental de modo fragmentado e setorializado, os sujeitos da pesquisa consideraram possível superar tais obstáculos com a persistência na defesa de uma modalidade de trabalho que investe na pactuação coletiva para a produção de respostas coletivas. Isso porque consideram que RIPS-Toledo tem trazido resultados positivos e proporciona mais segurança para os encaminhamentos, pela via da criação de protocolos e fluxos de atendimentos. Assim, os profissionais das políticas públicas setoriais podem estar mais próximos para a consecução do objetivo em aprimorar o atendimento destinado aos usuários. Com isso, consideram boas as expectativas quanto ao futuro desse trabalho intersetorial.

De acordo com os resultados obtidos, pode-se dizer que o conceito de pactuação é o elemento-chave para o processo de concretização de alianças e de constituição de pontos em comum entre as políticas setoriais que atuam na construção da RIPS-Toledo. Esta percepção foi bastante evidenciada pelos entrevistados quando enfatizaram a importância de uma construção horizontalizada para que haja o reconhecimento dos sujeitos, enquanto partícipes destas pactuações.

Como uma das descobertas mais significativas está o comprometimento desses profissionais que aceitaram o desafio de construir a articulação intersetorial e o trabalho em rede das políticas públicas no município de Toledo. Com a RIPS, vê-se que apesar das inúmeras dificuldades, muitos estão dispostos a mudar suas práticas em busca do atendimento integral aos usuários, $\mathrm{O}$ qual tenha correspondência com os direitos fundamentais previstos no Estatuto.

Dos aprendizados obtidos, resta a conviç̧ão de que a materialização da intersetorialidade nas redes de atendimento e de proteção precisa deixar de ser compreendida e operada como requisito personalíssimo decorrente das consultas, dos contatos, das interações e das alianças pessoais-profissionais. Urge avançar nas dimensões político-técnico-operativas das pactuações para conseguir tornar mais habitual a regência das práticas de implementação das políticas públicas embasadas pelos protocolos e fluxos de atendimento. Por fim, há a convicção de que é imprescindível dispor de conhecimentos que orientem a condução dos processos de pactuações para o fortalecimento das políticas públicas setoriais, cujos serviços e intervenções devem ter como escopo a preservação, a garantia e a proteção dos direitos humanos fundamentais de crianças e adolescentes, previstos na Convenção Internacional dos Direitos da Criança (1989) e no Estatuto da Criança e do Adolescente (1990).

\section{Referências}

AKERMAN, M.; SÁ, R. F.; MOYSES, S.; REZENDE, R.; ROCHA, D. Intersetorialidade? Intersetorialidades!

Ciência \& Saúde Coletiva. Rio de Janeiro, 19(11), p. 4291-4300, 2014. 
BAPTISTA, M.V. Algumas reflexões sobre o sistema de garantia de direitos. Serviço Social \& Sociedade. São Paulo, n. 109. p. 179-199, 2012.

BIDARRA, Z.S. Pactuar a intersetorialidade e tramar as redes para consolidar o sistema de garantia de direitos. Serviço Social \& Sociedade. São Paulo, n. 99, p. 483-497, 2009.

BIDARRA, Z.S. Conselhos gestores de políticas públicas: uma reflexão sobre os desafios para a construção dos espaços públicos. Serviço Social \& Sociedade. São Paulo, n. 88, p. 41-58, 2006.

BIDARRA, Z.S.; OLIVEIRA, L.V.N. As políticas públicas brasileiras e a questão da juventude. Emancipação. Ponta Grossa (PR), 13(2), p. 225-238, 2013.

BIDARRA Z.S.; CESCONETO E.A. Articulação extensão e pesquisa para construção da intersetorialidade entre políticas sociais no município de Toledo-PR. Expressa Extensão, v. 25, n. 1, p. 05-16, jan-abr., 2020.

BIDARRA Z.S.; CESCONETO E.A. Prática profissional do assistente social: pesquisa ação para construção da intersetorialidade entre políticas sociais. In: XXII Seminário Latinoamericano y del Caribe de Escuelas de Trabajo Social. Memorias [...]. Disponível em: https://conetsco.org/xxii-seminariolatinoamericano-trabajo-social/ Acesso em: 17 jul. 2020.

BOURGUIGNON, J.A. Concepção de Rede Intersetorial de atendimento à criança e ao adolescente. In: LAVORATTI, C. (org). Programa de Capacitação Permanente na área da Infância e da Adolescência: o germinar de uma experiência coletiva. Ponta Grossa (PR): UEPG, p. 245-251, 2007.

BRASIL. Planalto. Constituição da República Federativa do Brasil, 1988 e atualizações. Centro Gráfico do Senado Federal. Disponível em http://www.planalto.gov.br. Acesso em: 20 jun. 2020.

BRASIL. Ministério de Justiça. Lei no 8069, de 13 de julho de 1990 e atualizações. Dispõe sobre o Estatuto da Criança e do Adolescente e dá outras providências. Diário Oficial da União. Brasília, DF, 16 jul. 1990, e atualizações. Disponível em http://www.planalto.gov.br. Acesso em: 20 jun. 2020.

BRASIL. Ministério da Saúde. Secretaria de Vigilância em Saúde. Política Nacional de Promoção da Saúde (PNPS). Ministério da Saúde. Brasília (DF), 2006. Disponível em http://bvsms.saude.gov.br;bvs/ publicacoes/politica_promocao_saude.pdf. Acesso em: 20 jun. 2020.

BRASIL. Ministério de Desenvolvimento Social e Combate à Fome. Secretaria Nacional de Assistência Social. Política Nacional de Assistência Social (PNAS) e Norma Operacional Básica (NOBSUAS/2005). Brasília (DF), reimp, 2009.

BRASIL. Ministério da Previdência e Assistência Social. Programa de Combate ao Abuso e à Exploração Sexual de Crianças e Adolescentes - PROGRAMA "SENTINELA". Brasília: MPAS/SEAS, 2001.

BRASIL. Secretaria de Direitos Humanos da Presidência da República. Programa Nacional de Direitos Humanos (PNDH 1, 2 e 3). Secretaria de Direitos Humanos da Presidência da República. Brasília: SDH/ PR, 1996, 2002, 2009-2010.

BRASIL. Secretaria de Direitos Humanos da Presidência da República. Programa de Ações Integradas e Referenciais de Enfrentamento à Violência Sexual Infantojuvenil no Território Brasileiro: PAIR. MOTTI, A. (coord.). Brasília (DF): MS: Fundação Universidade Federal de Mato Grosso do Sul/ Secretaria de Direitos Humanos da Presidência da República, 2011.

CARNEIRO, C.B.L.; COSTA, B.L.D. Gestão social: o que há de novo? Belo Horizonte (MG): Fundação João Pinheiro, 2004. 
CONSELHO NACIONAL DOS DIREITOS DA CRIANÇA E DO ADOLESCENTE - CONANDA. RESOLUÇÃO no 113, de 19 de abril de 2006 - Dispõe sobre os parâmetros para a institucionalização e fortalecimento do Sistema de Garantia dos Direitos da Criança e do Adolescente.

DOURADO, A.L. A construção de protocolos como uma expressão do trabalho intersetorial: uma experiência no município de Toledo - Paraná. Trabalho de Conclusão de Curso (Bacharelado em Serviço Social) - Universidade Estadual do Oeste do Paraná/câmpus - Toledo, 2018.

DOURADO, A.L.; BIDARRA, Z.S. Rede Intersetorial para articulação do Sistema de Garantia de Direitos: uma experiência no município de Toledo-PR. In: III Simpósio Internacional Interdisciplinar em Ciências Sociais Aplicadas, 11 a 13 de setembro de 2019. Anais [...]. Ponta Grossa: SIICSA/UEPG. Ponta Grossa (PR), 2019. Disponível em: http://https://www2.uepg.br/ppgcsa/anais-do-simposio-internacionalinterdisciplinar-em-ciencias-sociais-aplicadas

FARINELLI, C.C.; PIERINI, A.J. O Sistema de Garantia de Direitos e a Proteção Integral à criança e ao adolescente: uma revisão bibliográfica. O Social em Questão. Ano XIX - n. 35, p. 63-86, 2016

FERRARI, A.K.; TAVARES, G.M. A aposta na tessitura de redes como inovação do trabalho no campo sociojurídico. Serviço Social \& Sociedade. São Paulo. n. 125, p. 101-123, 2016.

GONÇALVES, A.S.; GUARÁ, I. M. Redes de proteção social na comunidade. In: GUARÁ, I. M. (coord.). Redes de proteção social. São Paulo: Associação Fazendo História/NECA-PUC-SP, 2010.

GRAY, B. G. Collaborating: Finding Common Ground for Multiparty Problems. Retrieved from San Francisco, 1989.

IAMAMOTO, M.V. Renovação e Conservadorismo. São Paulo: Cortez, 1992.

INOJOSA, R. M. Intersetorialidade e a configuração de um novo paradigma organizacional. Revista de Administração Pública - RAP, 32(2), 35-48, 1998. Disponível em: http://bibliotecadigital.fgv.br/ojs/ index.php/rap/issue/view/834. Acesso em: 20 jun. 2020.

KALENGAONKAR, A.; BROWN, D. L. Intersectoral Cooperation: Lessons For Practice. Retrieved from Boston, Massachussetes, 2000. Disponível em: http://www.jsi.com/id Acesso: 20 jun. 2020.

LIPSKY, M. Toward a Theory of Street-Level Bureaucracy (IRP - Discussion Papers, n. 48-69). Madison, WI: Institute for Research on Poverty (IRP), University of Wisconsin. Retrieved. p. 45, 1969. Disponível em http://www.irp.wisc.edu/publications/dps/pdfs/dp4869.pdf Acesso em: 20 jun. 2020

MIOTO, R.C.T. O trabalho com redes como procedimento de intervenção profissional: o desafio da requalificação dos serviços. Revista Katalysis. Florianópolis (SC), v. 5, n. 1, p. 41-58, 2002.

MONNERAT, G. L.; SOUZA, R. G. Intersetorialidade e políticas sociais: um diálogo com a literatura atual. In: MONNERAT, G.L; ALMEIDA, N. L.T.; SOUZA, R. G. (orgs.). A intersetorialidade na agenda das políticas sociais. Campinas (SP): Papel Social, 2014. p. 41-54.

NETO, W.N. A Política Nacional de Direitos Humanos e sua incidência sobre as crianças e os adolescentes. In: Teses institucionais da Associação Nacional dos Centros de Defesa da Criança e do Adolescente (ANCED) - seção Brasil do Defense for Children International (DCI). 2015 (mimeo). Disponível em: http://www.conselhodacrianca.al.gov.br/sala-de-imprensa/noticias/2015/outubro-1/ a-politica-nacional-de-direitos-humanos-e-sua-incidencia-sobre-as-criancas-e-os-adolescentes Acesso em: 18 jun. 2020.

NETO, W.N. Instrumentos de promoção e proteção dos direitos da criança e do adolescente, enquanto direitos humanos especiais de geração. Instrumentos normativos internacionais 
de promoção e proteção: a Convenção sobre os Direitos da Criança. 2007 (mimeo). Disponível em: http://www.crianca.mppr.mp.br/arquivos/File/publi/xtras/direitos_humanos_de_geracao.pdf Acesso em: 18 jun. 2020.

PARANÁ. Secretaria da Família e Desenvolvimento Social. PLANO decenal dos direitos da criança e do adolescente do estado do Paraná: 2014-2023. Comitê Interinstitucional para Elaboração, Implementação e Acompanhamento do Plano Decenal dos Direitos da Criança e do Adolescente. (org.); Secretaria da Família e Desenvolvimento Social (Equipe Técnica). Curitiba: SEDS, 2013. 450 p.

PEREIRA, P.A.P. Política social: temas \& questões. 2.ed. São Paulo: Cortez, 2008.

PEREIRA, P.A.P. A intersetorialidade das politicas sociais na perspectiva dialética. In: MONNERAT, G.L; ALMEIDA, N. L.T.; SOUZA, R. G. (orgs.). A Intersetorialidade na Agenda das Políticas Sociais. Campinas (SP): Papel Social, 2014. p. 21-39.

REDE INTERSETORIAL DE PROTEÇÃO SOCIAL DE TOLEDO (RIPS). Memórias. Toledo/PR, 2016 (mimeo).

SALVADOR, E. Fundo público e políticas sociais na crise do capitalismo. Serviço Social \& Sociedade. São Paulo, n. 104, p. 605-631, out./dez. 2010.

SASSON. S.K.H.; BIDARRA, Z.S.; CESCONETO, E.A.; et. al. Iniciativa interinstitucional para a construção da rede intersetorial de proteção social de Toledo/PR (RIPS). In: $6^{\circ}$ Encontro Nacional do Serviço Social no Ministério Público. Anais [...]. 2016. Disponível em: https://documentos.mpsc.mp.br/portal/ manager/resourcesDB.aspx?path=2977

SPOSATI, A. Gestão pública intersetorial: sim ou não? Comentários de experiência. Serviço Social \& Sociedade. São Paulo, n. 85, p. 133-141, 2006.

TEIXEIRA, E.C. O local e o global: limites e desafios da participação cidadã. São Paulo: Cortez, 2001.

TUMELERO, S M. Estado, Produção do Espaço e Intersetorialidade: crítica e criação na implementação de políticas públicas. Tese. (Doutorado em Serviço Social) - Universidade Federal de Santa Catarina, Florianópolis (SC), 2015. 